\title{
Mechanical Properties of (SiC)p/Al Composite Fabricated by Sheath Rolling
}

\author{
Seong-Hee Lee*, Tetsuo Sakai and Yoshihiro Saito \\ Department of Materials Science and Engineering, Osaka University, Suita 565-0871, Japan
}

\begin{abstract}
Aluminum based MMC reinforced with SiC particles was fabricated by the sheath rolling method. A SUS304 stainless steel tube was used as a sheath. A tube was filled with a powder mixture of aluminum and reinforcement, reduced $75 \%$ in thickness by rolling at ambient temperature, and then sintered at $560^{\circ} \mathrm{C}$ for $1.8 \mathrm{ks}$. The composite was thermomechanically treated to improve its mechanical properties. The results of the present study were compared to those of $\mathrm{Al}_{2} \mathrm{O}_{3} / \mathrm{Al}$ composite fabricated by the same method. A powder compact of which the relative density was above 0.95 was obtained by cold sheath rolling only. After sintering, the tensile strength of the composites increased with increasing volume fraction of $\mathrm{SiC}$, and it reached a maximum of $100 \mathrm{MPa}$ which was $67 \%$ higher than that of the unreinforced material. The elongation decreased monotonously with increasing volume fraction of $\mathrm{SiC}$. Both the strength and the elongation for the composite were not improved by thermomechanical treatment. This means that the powder mixture had been consolidated already almost completely by the sheath rolling followed by sintering. The strengthening effect by reinforcement was also recognized at elevated temperatures.
\end{abstract}

(Received October 28, 1999)

Keywords: aluminum based metal matrix composite (MMC), sheath rolling, SiC/Al composite, powder compact, microstructure, mechanical property, thermomechanical treatment

\section{Introduction}

Metal matrix composites (MMCs) have attracted interests of many researchers due to their high specific strength, high wear resistance and good stability in high temperatures since sintered aluminum powder product (SAP) was invented. ${ }^{1)}$ Especially, aluminum based MMCs have been paid attention for their advantage of weight saving. In practical, particulate reinforced aluminum based MMCs are currently used in automotive drive shaft, equipment rack, brake rotor disc, bicycle frame, etc. ${ }^{2)}$ The possibility of using aluminum based MMCs to replace ferrous based materials for automotive powertrain and engine applications and structural components has also been explored. ${ }^{3)}$ However, the application of aluminum based MMCs to practical use is yet limited in specialized parts, is not extended to mass production.

Aluminum based MMCs are fabricated by liquid phase processes such as pressurized casting, ${ }^{4-7)}$ mixing of particles with molten metal ${ }^{8-11)}$ and in-situ reaction. ${ }^{12-16)}$ They are also fabricated by solid state processing such as consolidation of the mixture of reinforcement particle and metal powder. ${ }^{17-23)}$ The liquid phase processes are simple and thereby less expensive than solid state processing, while they have demerit that it is difficult to distribute reinforcement particles uniformly and to control content of reinforcement. On the other hand, powder metallurgical (P/M) route has a merit that content of reinforcement can be varied in wide range. In the $\mathrm{P} / \mathrm{M}$ route, it is necessary to break oxide film on the surface of metal particles for consolidating powder compact. Hot extrusion is often employed for this purpose in consolidation of aluminum powder. However, it is a batch process and has a limit in its productivity. The authors have proposed the sheath rolling as a method for consolidation of aluminum powder, ${ }^{24)}$ and have applied it to the fabrication of aluminum based MMC reinforced with $\mathrm{Al}_{2} \mathrm{O}_{3}$ particle. ${ }^{25)}$

\footnotetext{
${ }^{*}$ Graduate Student, Osaka University.
}

In the present study, aluminum based MMC reinforced with $\mathrm{SiC}$ particle was fabricated by the sheath rolling. It is now known that $\mathrm{SiC}$ has an excellent thermal conductivity and a corrosion resistance. It forms an adequate bond with the matrix without developing intermetallic phases because of its chemical compatibility with aluminum. ${ }^{26-31)}$ The SiC reinforced MMCs also show comparatively low cost, high machinability and good workability. ${ }^{32,33)}$ Therefore, the SiC particle has been often used as a reinforcement for aluminum based MMCs. This study was performed to investigate the mechanical properties of the SiC/Al composites fabricated by the sheath rolling process.

\section{Experimental Procedure}

\subsection{Preparation of specimen}

The nitrogen gas atomized high purity aluminum powder (Cu:1, Fe:1, Si:2, O:533 mass ppm, Al:bal), which was similar to that used in previous studies ${ }^{24,25)}$ was used as a matrix. Each particle had a nearly spherical shape. The mean particle diameter was $36 \mu \mathrm{m}$. The SiC particle with the size ranging from 2 to $4 \mu \mathrm{m}$ was used as reinforcement. The shape of the $\mathrm{SiC}$ particle was nearly equiaxed as shown in Fig. 1. The fabrication procedure of the composite is illustrated in Fig. 2. As details of the experimental procedure were given in previous study, ${ }^{25)}$ only a brief outline is described below. The volume fraction of the $\mathrm{SiC}$ particle was varied from 5 to $30 \%$. A blended powder of aluminium and $\mathrm{SiC}$ powders was mixed in rotating pot mill containing zirconia balls with the diameter of $5 \mathrm{~mm}$ for $7.2 \mathrm{ks}$ in dry condition after mixing for $7.2 \mathrm{ks}$ with methanol.

The powder mixture of metal matrix and reinforcement were filled in a stainless tube $300 \mathrm{~mm}$ in length with outer diameter of $12 \mathrm{~mm}$ and wall thickness of $1 \mathrm{~mm}$ by tapping. The powder in the tube was held at $370^{\circ} \mathrm{C}$ for $3.6 \mathrm{ks}$ in vacuum for degassing. After degassing, the tube was rolled to a shape of flat bar of $3 \mathrm{~mm}$ in thickness at ambient temperature by 9-pass 


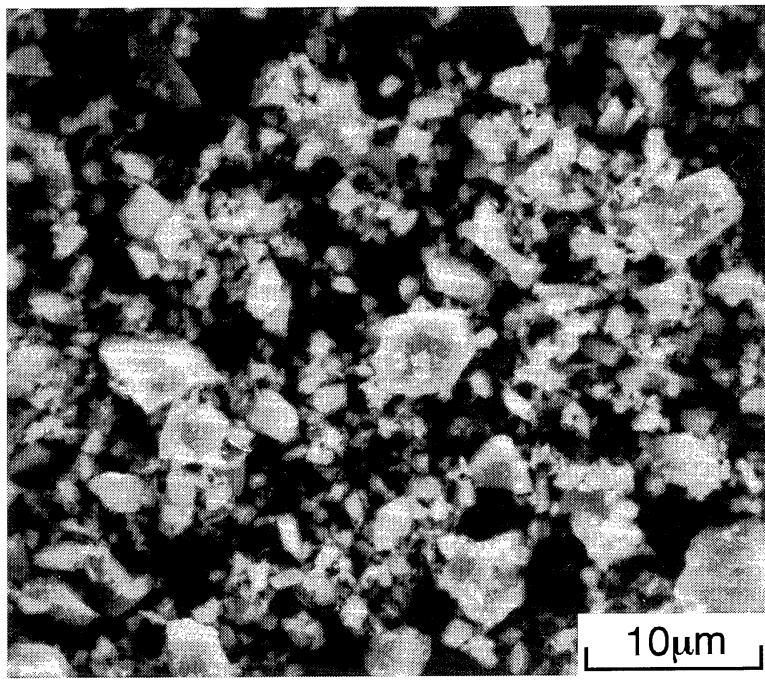

Fig. 1 SiC particles used as reinforcement.

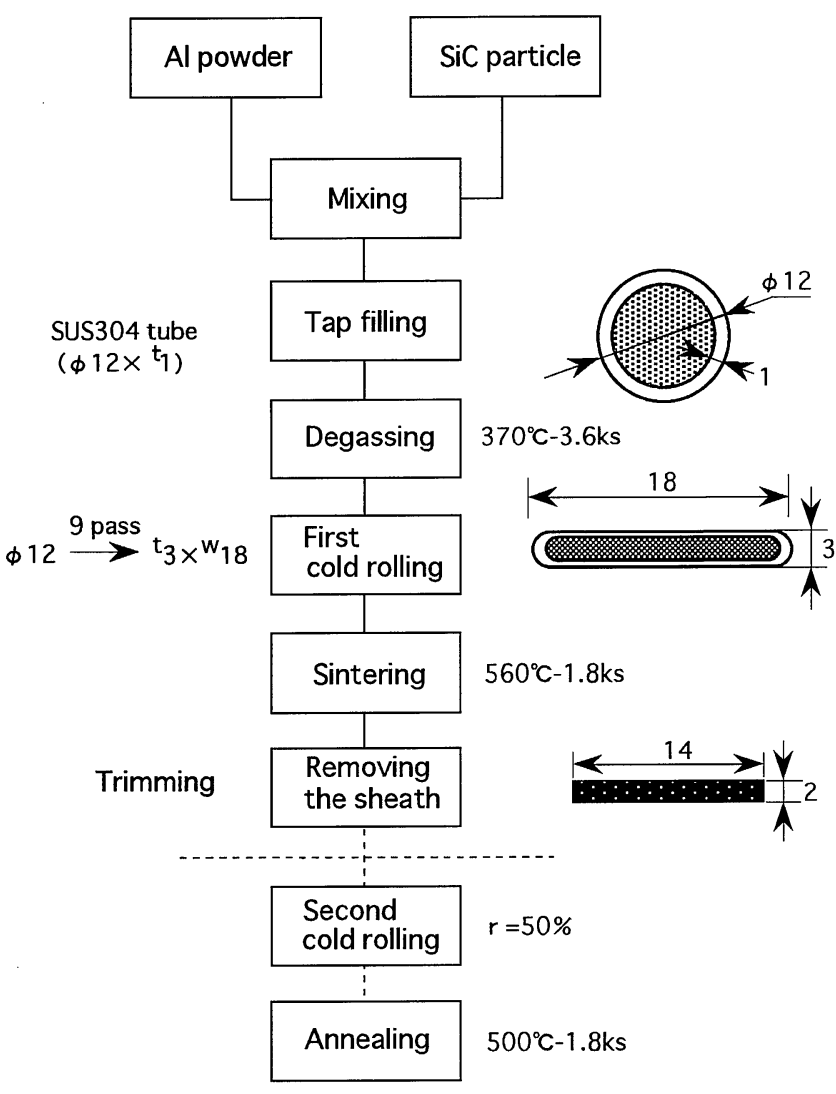

Fig. 2 Schematic illustration showing fabrication procedure of composite.

cold rolling. This cold rolling is designated as "the first cold rolling" in the present study. The first cold rolled specimen was sintered at $560^{\circ} \mathrm{C}$ for $1.8 \mathrm{ks}$. Then, the sintered specimens containing 5 to $20 \% \mathrm{SiC}$ were rolled to the reduction of $50 \%$ at ambient temperature. This cold rolling is designated as "the second cold rolling". The second cold rolled specimen was annealed at $500^{\circ} \mathrm{C}$ for $1.8 \mathrm{ks}$.

\subsection{Testing and characterization}

The relative density of the specimen was determined by
Archimedean densitometry. The mechanical properties at ambient temperature were determined by a tensile test. The specimen for the tensile test was spark cut after removing the sheath. The surface of the specimen was polished in order to obtain smooth surface. The length, width and thickness of reduced section was 15,6 and $1.7 \mathrm{~mm}$ respectively. The tensile test was conducted at the initial strain rate of $10^{-3} \mathrm{~s}^{-1}$. Fracture surface after the tensile test was observed by scanning electron microscope (SEM). Optical microstructures were revealed by electrical etching in dilute hydrofluoroboric acid and observed at the plane perpendicular to the transverse direction (TD plane). The distribution of reinforcement was also observed on the TD plane by SEM. For the sintered composites with volume fraction of 5 and $15 \% \mathrm{SiC}$, the tensile test in temperature range of 150 to $550^{\circ} \mathrm{C}$ was also conducted at the initial strain rate of $10^{-3} \mathrm{~s}^{-1}$.

\section{Results and Discussion}

\subsection{Distribution of reinforcements}

Figure 3 shows SEM photographs taken at the TD plane of the first cold rolled and sintered powder compact. At the volume fraction below $20 \%$, the $\mathrm{SiC}$ particles uniformly distributed,while clusters of $\mathrm{SiC}$ particle were observed at $30 \%$ reduction. In comparison with the $\mathrm{Al}_{2} \mathrm{O}_{3} / \mathrm{Al}$ composite which contained clusters of $\mathrm{Al}_{2} \mathrm{O}_{3}$ particle even at volume fraction of $20 \%,{ }^{25)}$ the $\mathrm{SiC}$ particles showed more uniform distribution though the similar mixing procedure was employed. This difference is probably due to the difference in particle shape. The $\mathrm{Al}_{2} \mathrm{O}_{3}$ particle had irregular shape which seemed to inhibit homogeneous mixing with aluminum powder. However, the SiC particle has comparatively equiaxed shape which is easy to distribute uniformly.

\subsection{Relative density of powder compacts after the first cold rolling and sintering}

The effect of volume fraction of $\mathrm{SiC}$ on relative density of powder compact after the first cold rolling and subsequent sintering is shown in Fig. 4. The relative density of the $\mathrm{Al}_{2} \mathrm{O}_{3} / \mathrm{Al}$ composite $^{25)}$ is also shown by broken line for comparison. Relative density of specimen is more than $95 \%$, which suggests that the powder compact is successfully consolidated by the first cold rolling. Especially, at the lower volume content, almost perfectly consolidated powder compact of which relative density is above $98 \%$ has been obtained. The relative density decreased with increasing the volume fraction of $\mathrm{SiC}$. At the higher volume fraction, the fall in relative density probably resulted from the clusters of $\mathrm{SiC}$ having pores between each particles. However, the fall was smaller than that in the $\mathrm{Al}_{2} \mathrm{O}_{3} / \mathrm{Al}$ composite, which is considered to be due to more homogeneous distribution of $\mathrm{SiC}$. The relitive density of the sintered specimen is higher than that of the first rolled specimen owing to densitification during sintering.

\subsection{Optical microstructures after first cold rolling and sintering}

Figure 5 shows optical microstructures observed at the TD plane of the powder compacts after the first cold rolling and subsequent sintering. Unreinforced powder compact after the 

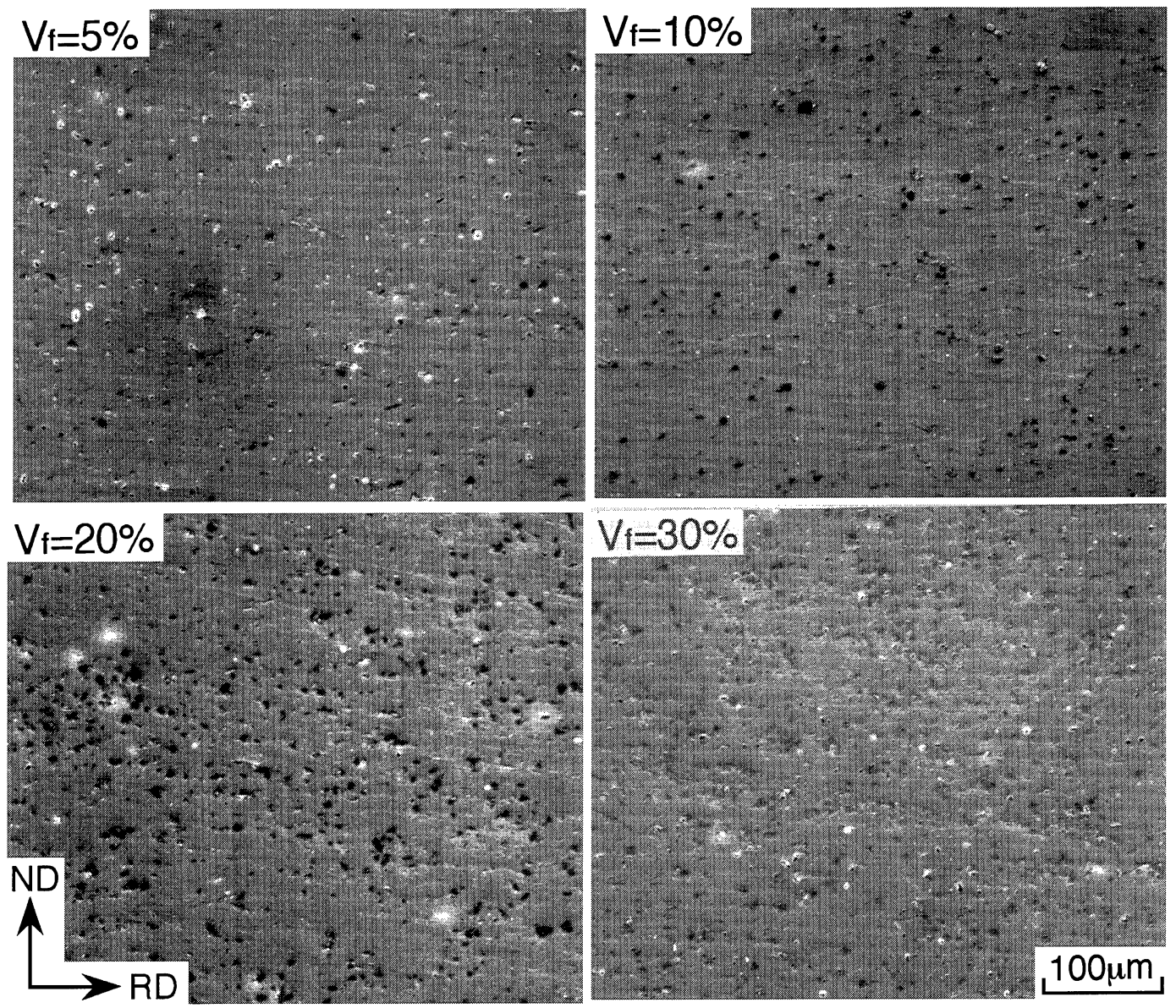

Fig. 3 SEM photographs taken at the TD plane after sintering showing distribution of SiC particles.

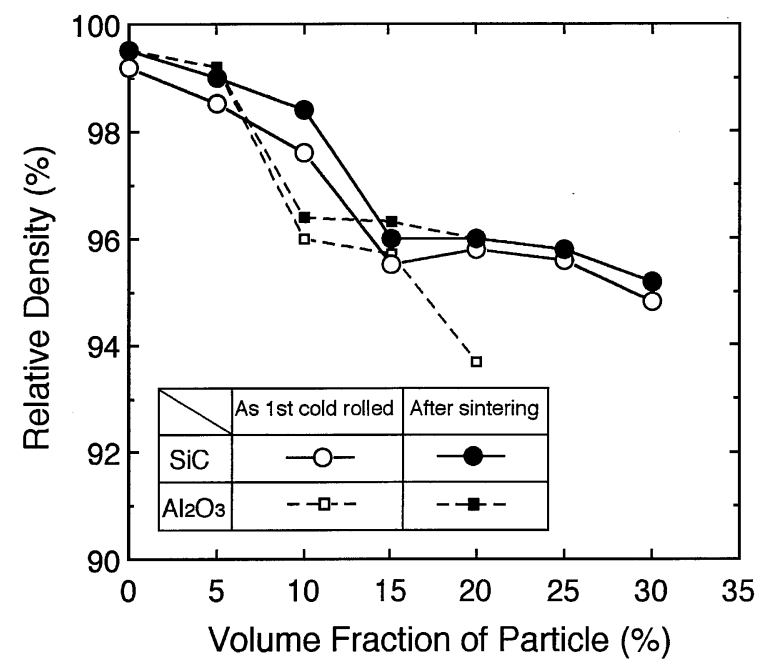

Fig. 4 Effect of volume fraction of $\mathrm{SiC}$ on relative density of specimen after first cold rolling and subsequent sintering.

first cold rolling shows deformation structure with elongated grains. However, in the $\mathrm{SiC}$ particle reinforced composites, the grain size is larger and their aspect ratio is smaller than those of unreinforced material. This shows that recrystallization occured in the reinforced materials. Because of accumulated deformation around the non-deformable reinforcements and the temperature rise of stainless sheath by plastic de- formation during cold rolling, the matrix of reinforced composites probably recrystallized. ${ }^{27)}$ In sintered specimen, each grain of unreinforced powder compact shows smooth grain boundaries and its size is larger than that of the cold rolled powder compact. This indicates that recrystallization occurs during sintering. However, the recrystallized grains do not have such equiaxed shape that the conventional recrystallized structure shows, but have elongated shape. This suggests that the grain boundary migration across the particle interface during grain growth is hard to occur.

\subsection{Mechanical properties after first cold rolling and sin- tering}

Figure 6 shows the effect of the volume fraction of $\mathrm{SiC}$ on the ultimate tensile strength, $0.2 \%$ proof stress and elongation of the specimen after the first cold rolling together with those of sintered specimen. The $0.2 \%$ proof stress, tensile strength and elongation of the cold rolled compact exceeds $70 \mathrm{MPa}$, $90 \mathrm{MPa}, 10 \%$ respectively at the volume fraction below $15 \%$. These results indicate that the mixtures of aluminum and $\mathrm{SiC}$ powders filled in stainless steel tube are successfully consolidated by the first cold rolling of which apparent reduction is $75 \%$, even if any heat treatment is not conducted. Contrary to the well known tendency of variation of strength with reinforcement content, the strength of the cold rolled composite does not increase monotonously with the volume fraction of $\mathrm{SiC}$. It decreases by addition of $5 \% \mathrm{SiC}$ and also decreases 

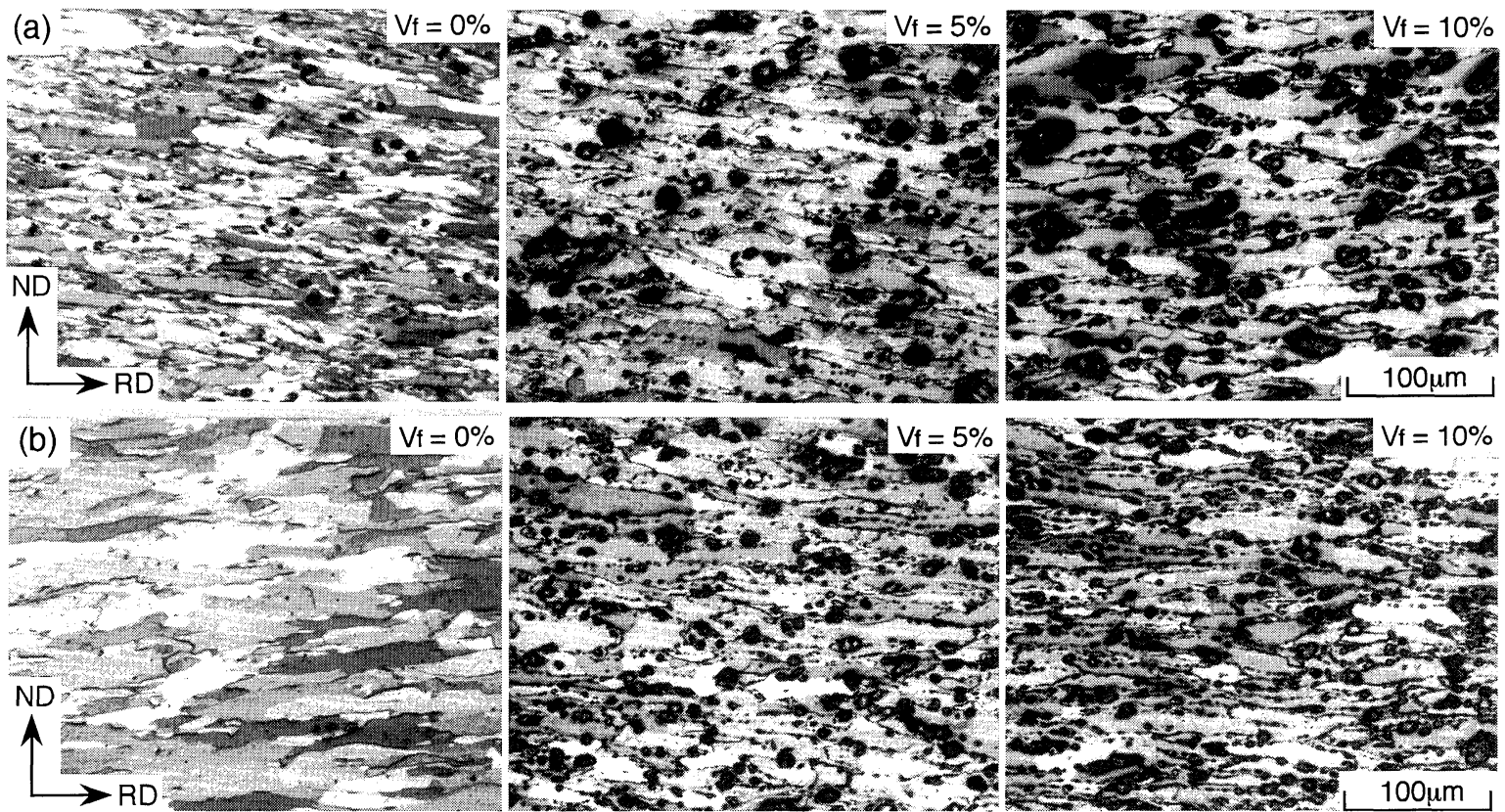

Fig. 5 Optical microstructures observed at the TD plane of the specimen after the first cold rolling (a) and subsequent sintering (b).

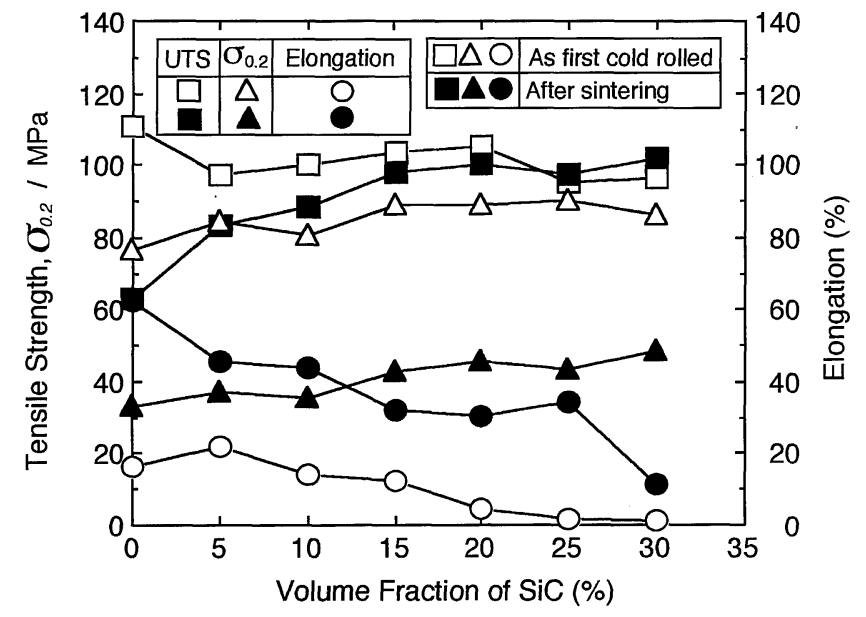

Fig. 6 Effect of volume fraction of $\mathrm{SiC}$ on mechanical properties of the specimen after the first cold rolling and subsequent sintering.

as the volume fraction of SiC particle increases 20 to $30 \%$. It increases with the volume fraction only in the range of 5 to $20 \%$. On the other hand, the elongation increases with addition of $5 \% \mathrm{SiC}$, but above $5 \%$ it decreases monotonously with increasing the volume fraction of $\mathrm{SiC}$. The decrease in proof stress and tensile strength and the increase in elongation at $5 \% \mathrm{SiC}$, are probably due to recrystallization or recovery promoted by temperature rise resulting from plastic work of stainless steel sheath during rolling and locally accumulated deformation near $\mathrm{SiC}$ particles as the $\mathrm{Al}_{2} \mathrm{O}_{3} / \mathrm{Al}$ composite showed. ${ }^{25)}$ The increase of strength with $\mathrm{SiC}$ content in the range of 5 to $20 \%$ was probably caused by the more enhanced strengthening due to particle reinforcement which canceled the softening by restoration of metal matrix. Above the volume fraction of $20 \%$, the decrease of yield stress, tensile strength and elongation is primarily due to particle cracking and interfacial debonding by cold rolling. The SiC parti-

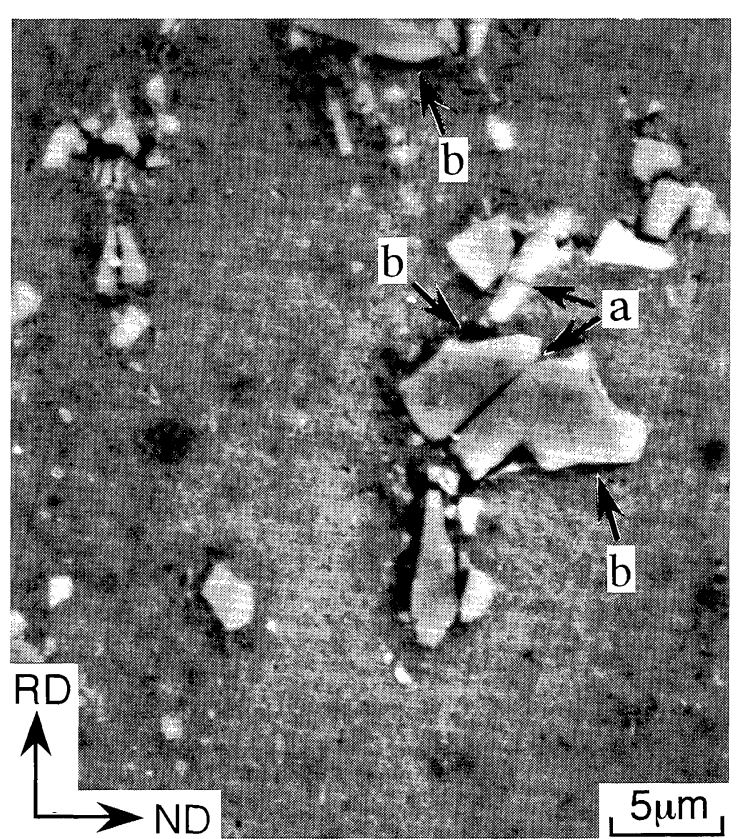

Fig. 7 SEM photograph showing SiC particle cracking (a) and interfacial debonding (b) occurred during the first cold rolling in the $25 \% \mathrm{SiC} / \mathrm{Al} \mathrm{com-}$ posite.

cle cracking and interfacial debonding occured during the first cold rolling in the $25 \% \mathrm{SiC} / \mathrm{Al}$ composite are shown in Fig. 7. The clusters of SiC particles that had been formed in the specimen also cause the deterioration of mechanical properties of powder compact.

The tensile strength and $0.2 \%$ proof stress of the composite after sintering are lower than those of the first cold rolled specimens because of the recrystallization of metal matrix during sintering. On the other hand, the elongation rises largely due to restoration by sintering and the enhanced adhesion between metal powders by diffusion at any volume frac- 

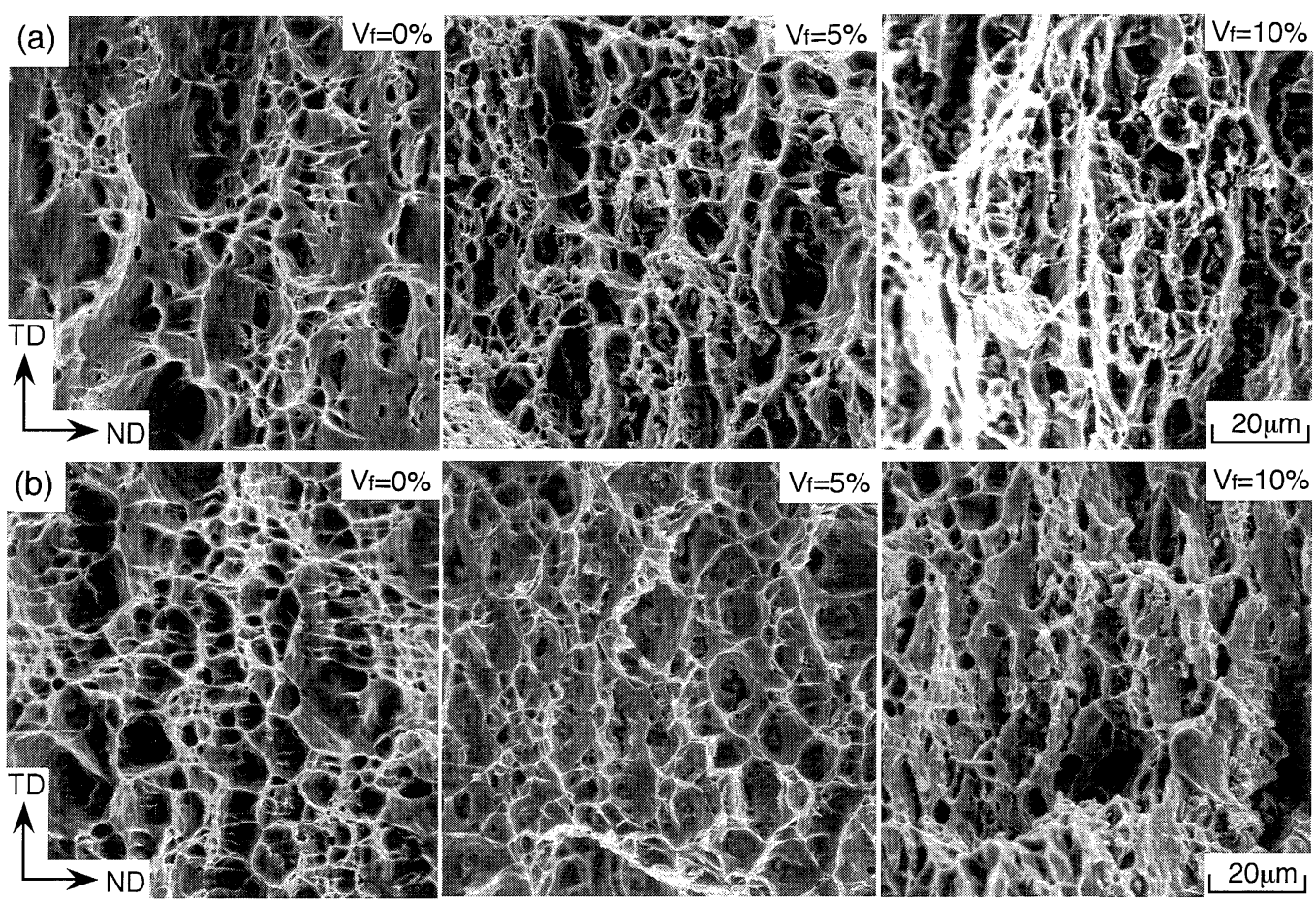

Fig. 8 SEM photographs showing fracture surfaces of specimen after the first cold rolling (a) and subsequent sintering (b).

tion. The enhanced adhesion between metal powders during sintering is also supported from increase in relative density by sintering, as shown in Fig. 4. The strength of the composite increases and elongation decreases with increasing the volume fraction of $\mathrm{SiC}$. After sintering, the composite is effectively strengthened by addition of $\mathrm{SiC}$ particles. The tensile strength of the composite above $15 \% \mathrm{SiC}$ shows $100 \mathrm{MPa}$ which is as high as $67 \%$ than that of unreinforced material. By the way, the unreinforced material after first cold rolling has a highest value of the strength in the present study. Therefore, it may seem that the fabrication of the high purity aluminum based SiC/Al composite by sheath rolling has no merit. However, it is thought that the sintered composite with the volume fraction of 15 to $25 \%$ is good for practical use from a viewpoint of balance of strength and ductility.

Figure 8 shows SEM photographs of fracture surfaces of the first cold rolled and the sintered specimen after tensile test. The aluminum matrix in composite after the first cold rolling shows ductile fracture surface, but some pores appear. This suggests that the powder mixture is not fully consolidated. On the other hand, the sintered specimen shows fracture surface covered with small dimples, suggesting that the bonding between aluminum powders progressed during sintering. For the composites with the volume fraction of 5 and $10 \%, \mathrm{SiC}$ particles are seen at the center of dimples, which indicates that the debonding initiates at boundary between matrix and reinforcement.

\subsection{Comparison of mechanical properties between $\mathrm{Al}_{2} \mathrm{O}_{3} / \mathrm{Al}$ and $\mathrm{SiC} / \mathrm{Al}$ composite}

Figure 9 shows a comparision of mechanical properties between sintered $\mathrm{Al}_{2} \mathrm{O}_{3} / \mathrm{Al}$ and $\mathrm{SiC} / \mathrm{Al}$ composites. The strengthening efficiency of $\mathrm{SiC}$ particle is better than that

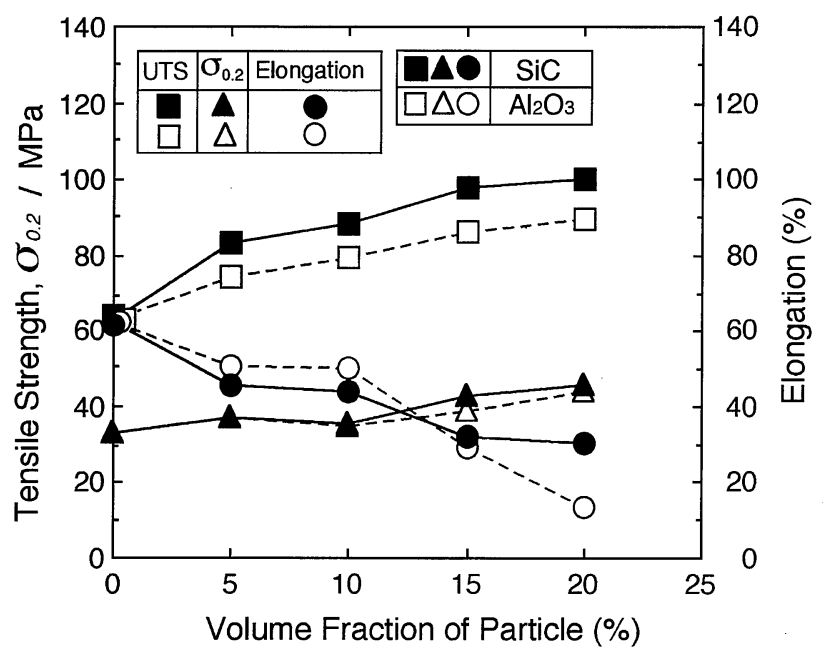

Fig. 9 Comparison of mechanical properties between the SiC/Al and $\mathrm{Al}_{2} \mathrm{O}_{3} / \mathrm{Al}$ composite after sintering.

of $\mathrm{Al}_{2} \mathrm{O}_{3}$ particle, since the tensile strength of the $\mathrm{SiC} / \mathrm{Al}$ composite is higher than that of the $\mathrm{Al}_{2} \mathrm{O}_{3} / \mathrm{Al}$ composite. From what does this difference of ultimate tensile strength between the $\mathrm{Al}_{2} \mathrm{O}_{3} / \mathrm{Al}$ and $\mathrm{SiC} / \mathrm{Al}$ composites arise? By Arsenault ${ }^{34)}$ the following expression was proposed for the ultimate strength of composites

$$
\sigma_{\mathrm{UTS}}=\sigma_{\mathrm{disl}}+\sigma_{\mathrm{sg}}+\sigma_{\mathrm{wh}}+\sigma_{\mathrm{comp}}+\sigma_{\mathrm{ah}}
$$

where $\sigma_{\text {disl }}$ is the term due to dislocation density before working; $\sigma_{\mathrm{sg}}$ is due to subgrain boundaries; $\sigma_{\mathrm{wh}}$ is the increase due to work hardening; $\sigma_{\text {comp }}$ is due to continuum mechanics strengthening; and finally $\sigma_{\mathrm{ah}}$ is due to the heat treatment. In present study, the experimental schedule is identical with that 
of the $\mathrm{Al}_{2} \mathrm{O}_{3} / \mathrm{Al}$ composite in previous study. Only the type, the size and shape of reinforcement used are different from that of previous study. Therefore, the terms $\sigma_{\text {disl }}, \sigma_{\text {sg }}, \sigma_{\text {comp }}$, and $\sigma_{\text {ah }}$ do not cause difference in tensile strength. There are some reports that the dislocations are generated by the thermal strain induced by difference in coefficient of thermal expansion (CTE) of matrix and reinforcement during cooling. ${ }^{35-37)}$ However, the dislocations generated around reinforcement by difference in CTE were not recognized by transmission electron microscopy in both composites. Therefore, the difference in ultimate tensile strength for both composites is considered to be due to work hardening. The locally accumulated strain is generated around reinforcement particles in the metal matrix composite. The size of SiC particle is smaller than that of $\mathrm{Al}_{2} \mathrm{O}_{3}$ particle (the mean diameter of $\mathrm{Al}_{2} \mathrm{O}_{3}$ particle was $\left.4.6 \mu \mathrm{m}\right){ }^{25)}$ Therefore, the number of the $\mathrm{SiC}$ particles in the $\mathrm{SiC} / \mathrm{Al}$ composite is larger than that of $\mathrm{Al}_{2} \mathrm{O}_{3}$ particles in the $\mathrm{Al}_{2} \mathrm{O}_{3} / \mathrm{Al}$ composite. This means that the strain hardening of the $\mathrm{SiC} / \mathrm{Al}$ composite is larger than that of the $\mathrm{Al}_{2} \mathrm{O}_{3} / \mathrm{Al}$ composite during tensile test.

Figure 10 shows stress-strain curves for each composite. The true stress of the $\mathrm{SiC} / \mathrm{Al}$ composites is higher than that of the $\mathrm{Al}_{2} \mathrm{O}_{3} / \mathrm{Al}$ composites at all of volume fractions. Especially, the difference in true stress between both composites is very large at volume fraction of 10 and $15 \%$. For many ductile metals which are fully annealed, the relationship between stress and strain is descrived by following form at constant strain rate.

$$
\sigma=k \varepsilon^{n}
$$

where $n$ is defined as the strain-hardening exponent and $k$ is often called the strength coefficient. Table 1 shows values of $n$ and $k$ in two composites obtained from the stress-strain curves. The values of $n$ and $k$ are higher in the SiC/Al composites than in the $\mathrm{Al}_{2} \mathrm{O}_{3} / \mathrm{Al}$ composite, as shown in Table 1 . The difference of $n$-value between both composites at volume fraction of 10 and $15 \%$ is not so large as that in other volume fraction. Therefore, the large difference in the true stress at volume fraction of 10 and $15 \%$ between two composites is mostly due to the difference in value of $k$. The lower values of $n$ at higher volume fraction in both composites are probably caused by clusters (pores) of reinforcement. ${ }^{38)}$ On the other hand, another factor such as difference in property of metal/ceramic interface must be considered. From what this difference in strength arises is not clear in the present study. The effect of particle content on the correlation between tensile strength and elongation of the specimen after sintering is illustrated in Fig. 11. At lower content, the correlation is similar in both the $\mathrm{Al}_{2} \mathrm{O}_{3} / \mathrm{Al}$ and $\mathrm{SiC} / \mathrm{Al}$ composites. At higher content, the $\mathrm{SiC} / \mathrm{Al}$ composite has large elongation and high strength. Therefore, the $\mathrm{SiC}$ is more effective to reinforce alu-

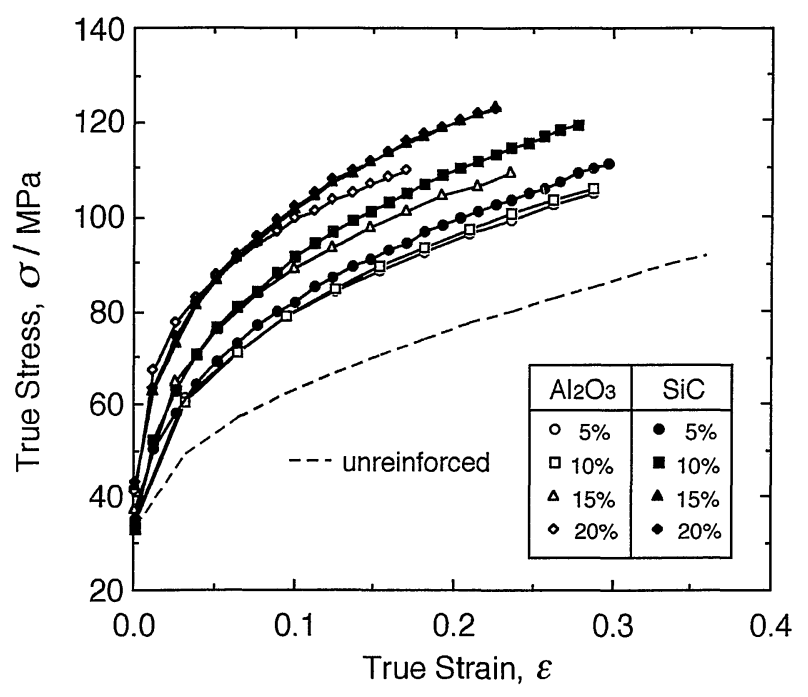

Fig. 10 The comparison of stress-strain curves between $\mathrm{Al}_{2} \mathrm{O}_{3} / \mathrm{Al}$ and $\mathrm{SiC} / \mathrm{Al}$ composites.

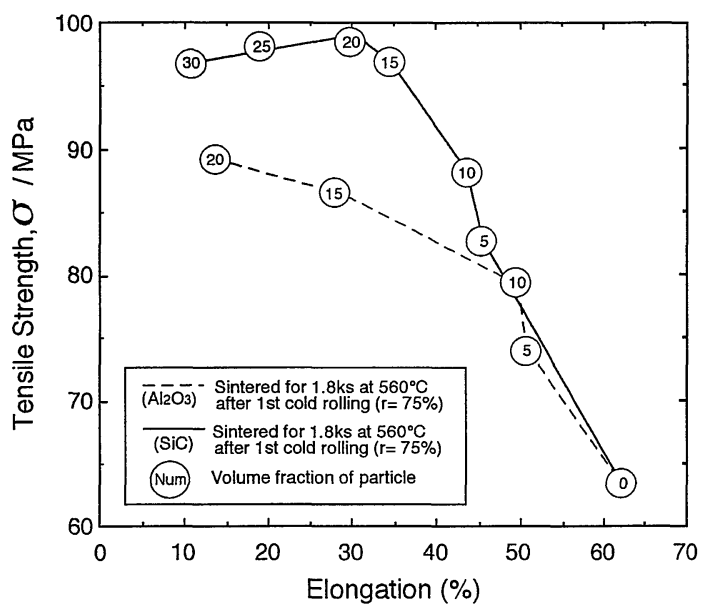

Fig. 11 Correlation between tensile strength and elongation of sintered specimen.

minum matrix when the MMC is fabricated by the first cold rolling and sintering.

\subsection{Effect of thermomechanical treatment on mechani- cal properties and structures of composites}

The sintered composite was cold rolled to $50 \%$ and annealed for $1.8 \mathrm{ks}$ at $500^{\circ} \mathrm{C}$ after removing the stainless steel sheath. Figure 12 shows effect of the volume fraction of $\mathrm{SiC}$ on the relative density of the composite after second cold rolling and subsequent annealing. The results of relative density of the specimen after the first cold rolling and subsequent sintering are plotted again for comparison. The relative den-

Table 1 The comparison of $n$ values and $k$ values between $\mathrm{Al}_{2} \mathrm{O}_{3} / \mathrm{Al}$ and $\mathrm{SiC} / \mathrm{Al}$ composites.

\begin{tabular}{|c|c|c|c|c|c|c|c|c|c|c|}
\hline \multirow{2}{*}{$\begin{array}{l}\text { Volume fraction of } \\
\text { reinforcement }\left(V_{\mathrm{f}}\right)\end{array}$} & \multicolumn{2}{|c|}{0} & \multicolumn{2}{|c|}{5} & \multicolumn{2}{|c|}{10} & \multicolumn{2}{|c|}{15} & \multicolumn{2}{|c|}{20} \\
\hline & $k / \mathrm{MPa}$ & $n$ & $k / \mathrm{MPa}$ & $n$ & $k / \mathrm{MPa}$ & $n$ & $k / \mathrm{MPa}$ & $n$ & $k / \mathrm{MPa}$ & $n$ \\
\hline $\mathrm{Al}_{2} \mathrm{O}_{3} / \mathrm{Al}$ & 30.9 & 0.22 & 44.1 & 0.23 & 45.3 & 0.25 & 51.4 & 0.23 & 64.0 & 0.19 \\
\hline $\mathrm{SiC} / \mathrm{Al}$ & 30.9 & 0.22 & 44.0 & 0.27 & 49.0 & 0.27 & 58.1 & 0.25 & 59.4 & 0.24 \\
\hline
\end{tabular}




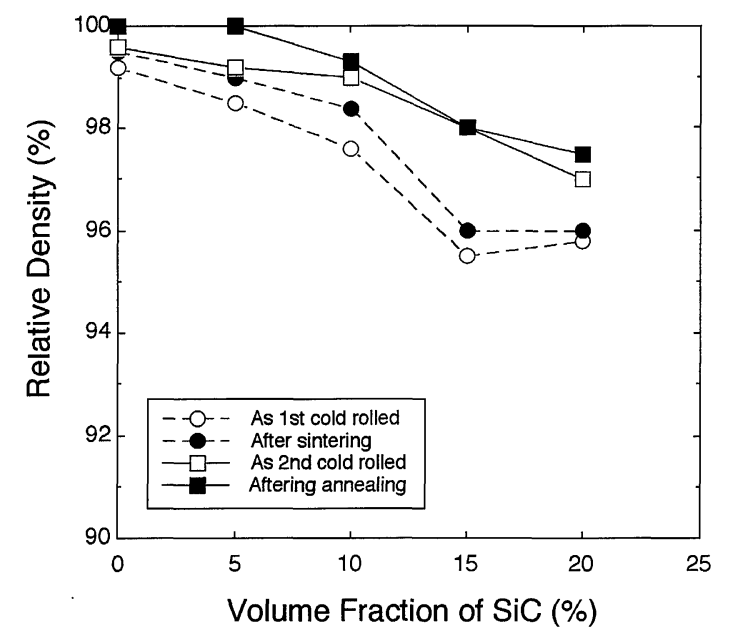

Fig. 12 Effect of the volume fraction of SiC on relative density of the specimen after the second cold rolling and annealing.

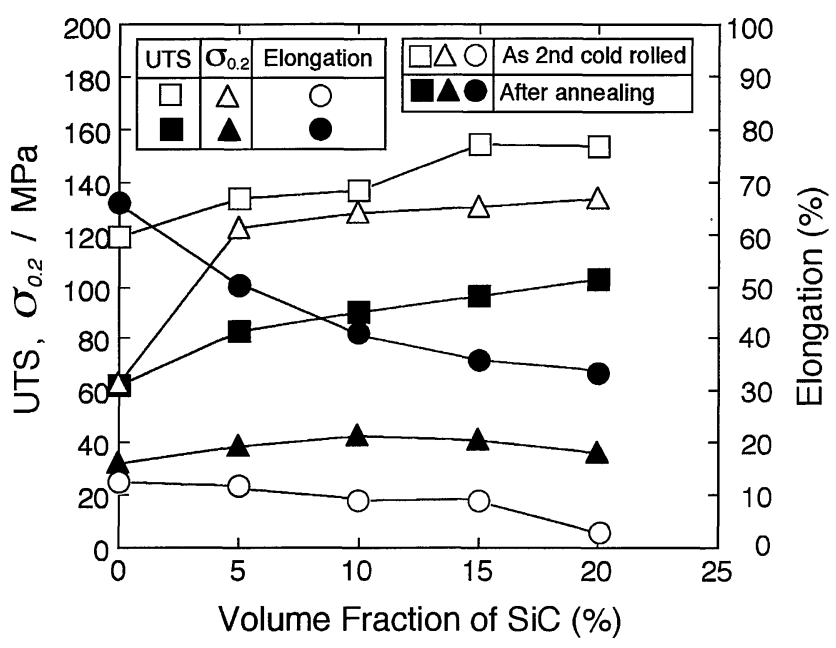

Fig. 13 Mechanical properties of the specimen after the second cold rolling and annealing.

sity of the composite is raised by the second cold rolling and subsequent annealing because the relative density of consolidated metal matrix increases during cold rolling and subsequent annealing. But it decreases with increasing the volume fraction of SiC. This is due to reinforcement fractures and cracks formed during the second cold rolling. Interfacial debonding between matrix and reinforcement induced by tensile strain along the rolling direction is also detrimental to the density of the composite. These reinforcement cracking and interfacial debonding increase with the volume fraction of $\mathrm{SiC}$, results in fall of density at high volume fractions.

The change in mechanical properties with the second cold rolling and subsequent annealing is shown in Fig. 13. Because the cold rolled specimen is strengthened by work hardening, the tensile strength and the proof stress are higher than those of the sintered specimen shown in Fig. 6. The tensile strength of the cold rolled specimen increases with the volume fraction of $\mathrm{SiC}$. This rise in strength seems to be caused partly by enhanced work hardening around reinforcement particles. Corresponding to the increase of strength, the elongation de-

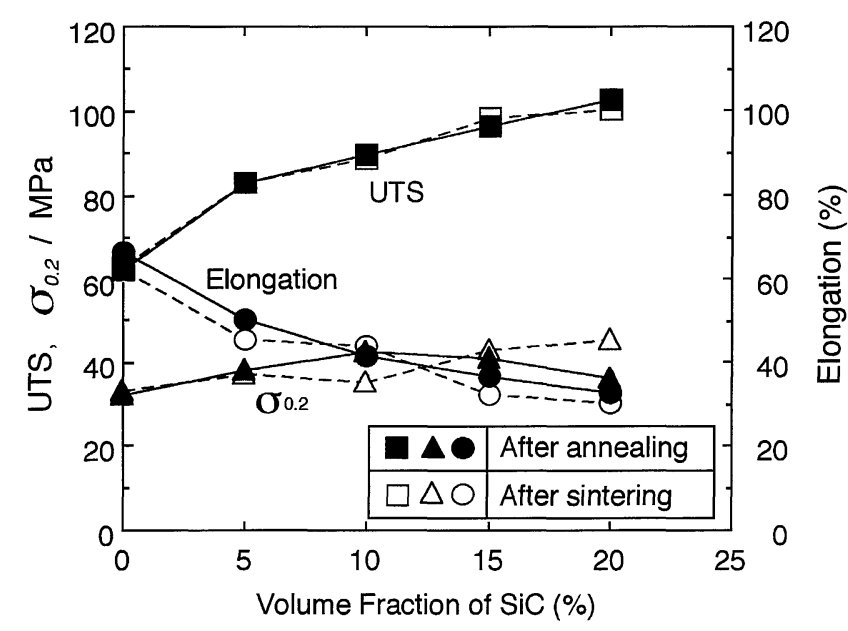

Fig. 14 Mechanical properties of the annealed specimen (broken line: mechanical properties of sintered specimen).

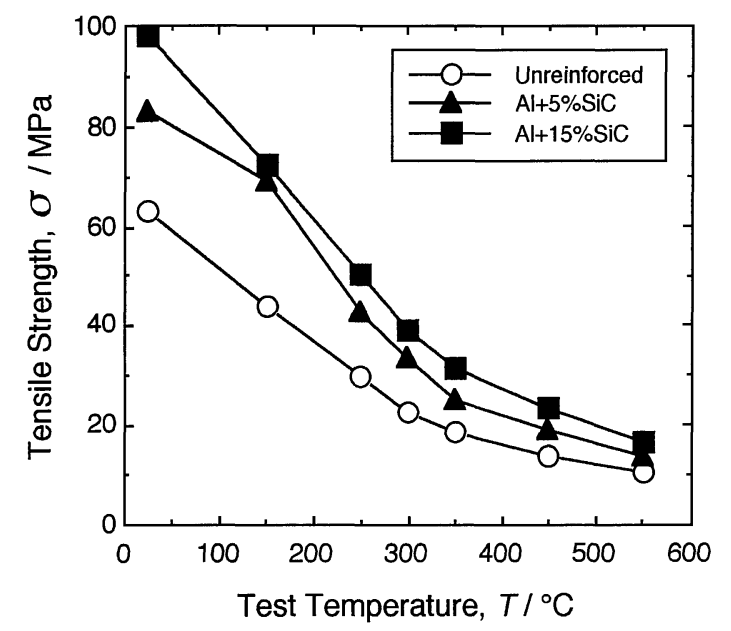

Fig. 15 Changes in tensile strength of sintered specimen with tensile test temperature.

creases with the volume fraction of $\mathrm{SiC}$. The $0.2 \%$ proof stress of specimen shows sharp rise at $5 \% \mathrm{SiC}$, above which it increases gradually as the volume fraction of $\mathrm{SiC}$ increases. This sharp rise in the proof stress at $5 \% \mathrm{SiC}$ is probably due to excess work hardening induced by $\mathrm{SiC}$ particles. ${ }^{16,17)}$

The annealing for $1.8 \mathrm{ks}$ at $500^{\circ} \mathrm{C}$ results in fall in the strength and $0.2 \%$ proof stress caused by restoration of metal matrix. However, the elongation rises largely, becomes more than $30 \%$. As the volume fraction of $\mathrm{SiC}$ increases, the strength of annealed specimen increases and its elongation decreases. Figure 14 shows a comparison of mechanical properties between the sintered specimen and the annealed specimen. The tensile strength and the $0.2 \%$ proof stress of the annealed specimen are nearly equivalent to those of the sintered specimen even if its elongation is slightly higher than that of the sintered specimen. These results are different from those in the $\mathrm{Al}_{2} \mathrm{O}_{3} / \mathrm{Al}$ composite of which mechanical properties were improved by thermomechanical treatment. This suggests that for the $\mathrm{SiC} / \mathrm{Al}$ composite, powder compact by sheath rolling has been already consolidated almost completly during sintering after the first cold rolling. 


\subsection{Tensile properties at elevated temperatures}

Figure 15 shows the changes of tensile strength of the sintered specimen with tensile test temperature. The tensile strength of the composites decreases with increasing test temperature at any volume fraction. And at any test temperature, the higher the volume fraction of the SiC particles is, the larger the tensile strength of the composites is. This means that the $\mathrm{SiC}$ particle is effective for strengthening MMC even at elevated temperatures.

\section{Conclusions}

The mechanical properties of the SiC/Al composite fabricated by sheath rolling process were investigated. The results obtained were summarized as follows.

(1) The tensile strength of the $\mathrm{SiC} / \mathrm{Al}$ composites fabricated by the sheath rolling and sintering increased with increasing the volume fraction of $\mathrm{SiC}$, and it reached the maximum of $100 \mathrm{MPa}$ which was $67 \%$ higher than that of unreinforced material.

(2) The tensile strength of the $\mathrm{SiC} / \mathrm{Al}$ composite was higher than that of the $\mathrm{Al}_{2} \mathrm{O}_{3} / \mathrm{Al}$ composite.

(3) The tensile strength of the SiC/Al composite fabricated by sheath rolling and subsequently sintering was not improved by thermomechanical treatment. This means probably that the powder mixture has been already consolidated almost completely by the sheath rolling followed by sintering.

(4) For the SiC/Al composite by the sheath rolling, the strengthening effect by reinforcement was also recognized at elevated temperatures.

\section{REFERENCES}

1) E. A. Bloch: Metall. Rev., 6 (1961), 193-239.

2) T. W. Clyne and P. J. Withers: An introduction to Metal Matrix Composites, Cambridge Solid State Science Series, Cambridge University Press, Cambridge, (1993), pp. 454-471.

3) I. J. Palmear: Light Alloys, Arnold, London, (1995), pp. 320-328.

4) T. W. Clyne and J. F. Mason: Metall. Trans. A, 18A (1987), 1519-1530.

5) A. Mortensen and J. A. Cornie: Metall. Trans. A, 18A (1987), 11601163.

6) M. K. Aghajanian, M. A. Rocazella, J. T. Burke and S. D. Keck: J. Mater. Sci., 26 (1991), 447-455.
7) E. M. Klier, A. Mortensen, J. A. Cornie and M. C. Flemings: J. Mater. Sci., 26 (1991), 2519-2526.

8) R. Mehrabian, R. G. Riek and M. C. Flemings: Metall. Trans. A, 5A (1974), 1899-1905.

9) C. G. Levi, G. S. Abbaschian and R. Mehrabian: Metall. Trans. A, 9A (1978), 697-711.

10) P. K. Rohatgi, R. Asthana and S. Das: Int. Met. Rev., 31 (1986), 115139.

11) Y. Genma, Y. Tsunekawa, M. Okumiya and N. Mohri: Mater. Trans., JIM, 68 (1997), 232-239.

12) F. R. Mollard and M. C. Flemings: Trans. Metall. Soc. AIME, 239 (1967), 1526-1533.

13) A. R. C. Westwood: Metall. Trans. A, 19A (1988), 749-758.

14) P. Sahoo and M. J. Koczak: Mater. Sci. Eng., A131 (1991), 69-76.

15) M. R. Hanabe and P. B. Aswath: J. Mater. Res., 11 (1996), 1562-1569.

16) H. Nakata, T. Chou and N. Kanetake: J. Mater. Sci., 30 (1995), 17191727.

17) A. P. Divencha, S. G. Fishman and S. D. Karman: J. Met., 33 (1981), 12-17.

18) N. C. Kothari: J. Nuclear Mater., 22 (1967), 165-176.

19) N. C. Kothari: Powder Metall. Int., 18 (1986), 321-325.

20) A. Niklas, L. Froyen, L. Delaey and L. Buekenhout: Mater. Sci. Eng., A135 (1991), 225-229.

21) S. H. Hong and K. H. Chung: Mater. Sci. Eng., A194 (1995), 165-170.

22) T. A. Baker, A. J. Gorton, Y.Song, X. Ni, M. H. Carvalho, T. M. Marcelo and H. Carvalhinhos: Powder Metall., 39 (1996), 223-229.

23) G. R. Shaik and W. W. Milligan: Metall. Trans. A, 28A (1997), 895904.

24) T. Sakai, S. H. Lee and Y. Saito: Mater. Trans., JIM, 39 (1998), 11971205.

25) S. H. Lee, T. Sakai and Y. Saito: Mater. Trans., JIM, 39 (1998), 12061213.

26) S. R. Nutt and R. W. Carpenter: Mater. Sci. \& Eng., 75 (1985), 169177.

27) S. V. Nair, J. J. Tien and R. C. Bates: Int. Met. Rev., 30 (1985), 275-288.

28) J. C. Romero, L. Wang and R. J. Arsenault: Mat. Sci. \& Eng., A212 (1996), 1-5

29) J. C. Viala, P. Fortier and J. Bouix: J. Mat. Sci. 25 (1990), 1842-1850.

30) C. A. Handwerker, M. D. Vaudin, U. R. Kattner and D. J. Lee: in Metal Ceramic Interface, ed. by M. Muhle, A. G. Evans, M. F. Ashby and J. P. Hirth (Pergamon Press), New York, (1990), pp. 129-137.

31) T. Iseki, T. Kameda and T. Maruyama: J. Mat. Sci., 19 (1984), 16921698.

32) David L. McDanels: Metall. Trans. A, 16A (1985), 1105-1115.

33) A. D. Divecha, S. G. Fishman and S. D. Karmarkar: J. Met., 33 (1981), 12-17.

34) R. J. Arsenault: Mater. Sci. Eng., 64 (1984), 171-181.

35) Y. Flom and R. J. Arsenault: J. Met., 7 (1986), 31-34.

36) Mary Vogelsang, R. J. Arsenault and R. M. Fisher: Metall. Trans.A, 17A (1986), 379-389.

37) R. J. Arsenault and R. M. Fisher: Scr. Metall., 17 (1983), 67-71.

38) M. Vedani and E. Gariboldi: Acta Mater., 44 (1996), 3077-3088. 